\title{
Studies on waterfront advances in sub surface drip irrigation under laboratory conditions
}

\author{
M. SRINIVASULU, A. RAMARAO, K. KISHAN AND H.V. HEMA KUMAR
}

\begin{abstract}
Proper utilization of water is very much essential to fight against the future water scarcity. India inhabits 16 per cent of the total world population with only 2 per cent of the total land and 4 per cent of the total water resources of the world. The per capita availability of water in India is $1820 \mathrm{cu}$. m per year whereas, it is $1700 \mathrm{cu}$. m per year in Orissa state. Subsurface drip irrigation is a better technology over the surface drip irrigation system. In case of SSDI system, laterals are placed at such a depth that wetting front water lies at least 10-15 $\mathrm{cm}$ below the soil surface, thus applying water directly into the root zone and leaving $10-12 \mathrm{~cm}$ of surface profile dry. In this system evaporation loss is reduced and thus improves irrigation efficiency by around 30 per cent over conventional drip system. Weed growth is little or fully checked due to dryness of upper soil layer. SSDI has advantages like quack plant response to nutrient application, trafficability in the field. Subsurface drip irrigation has also the potential to deliver low fertilizer rates over extended time periods with increased nutrient efficiency and reduces the leaching of nutrient below the root zone with lower cost per harvested unit. As a further development, a new irrigation method namely subsurface drip irrigation with perforated Linear Low Density Polyethylene (LLDP) tube in sand and gravel tubes is expected to increase the water use efficiency of subsurface applied drip irrigation on permanent tree crops. In this case, the micro tube emitter fitted into the lateral will be buried into the perforated LLDP tube in soil near to the plant root zone and there by evaporation losses can be completely avoided. Study of water front advances with micro tube emitter embedded in perforated LLDP tube placed in the soil, in perforated LLDP tube placed in sand tube, in perforated LLDP tube placed in fine gravel tube and placed on sand tube and fine gravel tube were reported in this article.
\end{abstract}

KEY WORDS : Waterfront, Subsurface drip-irrigation, Laboratory conditions

How to cite this Article : Srinivasulu, M., Ramarao, A. Kishan, K. and Kumar, H.V. Hema (2014). Studies on waterfront advances in sub surface drip irrigation under laboratory conditions Engg. \& Tech. in India, 5 (1\&2) : 1-9. 